The purpose of $\boldsymbol{A}$ Reference Guide for English Studies is to introduce and describe unfamiliar reference sources that one may consult when dealing with any reference question arising from current teaching or research in any branch of English studies. For these purposes, English studies are defined as all those subjects and lines of critical and scholarly inquiry presently pursued by members of university departments of English language and literature. Put more boldly, this work aims to provide more help to more people than any single reference guide we in English studies have hitherto possessed.

\section{HISTORY OF THE PROJECT}

The work's title echoes that of Donald F. Bond's Reference Guide to English Studies, 2d ed. (1971) (see entry A-11), itself a more current version of the earliest work of this kind, Tom Peete Cross's List of Books and Articles, Chiefly Bibliographical, Designed to Serve as an Introduction to the Bibliography and Methods of English Literary History, first published in 1919 and revised every few years through mid-century. Indeed, the present volume began as a supplement to sheer-list student reference guides such as Bond's; the Selective Bibliography for the Study of English and American Literature by Richard D. Altick and Andrew Wright, 6th ed. (1979) (A-10); and A Concise Bibliography for Students of English by Arthur G. Kennedy and Donald B. Sands, 5th ed., rev. William E. Colburn (1972) (A-12). My original aim was to supplement these lists with descriptions sufficient to alert students to the characteristics and thus the potential uses of key reference works. Armed with such descriptions, beginning researchers would, I thought, spend less time consulting numbers of works that might possibly be of use and more time using appropriate tools to solve problems. I further anticipated that instead of relying on the reference librarian, students would use the guidance of my descriptions to become more self-sufficient in the research library.

A few years after I began composing and distributing mimeographed "summary characterizations," as I called those supplementary descriptions, two books were published that had similar intentions. First in 1976 came Margaret Patterson's Literary Research Guide (see A-14), and then in 1977 came the United States publication of Robert C. Schweik and Dieter Riesner's Reference Sources in English and American Literature: An Annotated Bibliography (A-16), which had been issued in Germany the previous year.

When I compared my "summary characterizations" with the annotations in these two books, I found that though our intentions were similar, I had a different view of the kind and amount of information that students might require in a reference guide for English studies. And when my students worked with first the one and then the other published guide, they discovered also that the brevity and descriptive character of their annotations-designed to help readers know about a work-were less helpful than my fuller and more dynamic, user-oriented summaries in making decisions about which tools to consult and in what order.

What we discovered was the difference between a guide designed for the use of a hypothetical beginner-deliberately and consistently introductory in its perspective on the discipline-and a guide available to the beginner but intended for a wider, more experienced audience and more than introductory use.

\section{USE OF THIS GUIDE}

The present work is of this more ambitious kind. It assumes serious use by students who are beginners only in their unfamiliarity with the material and who seek more than a passing acquaintance with the tools of their discipline. For it has become my view that the best way to educate the apprentice is to treat him or her as a junior colleague. To reduce or simplify goals in order to accommodate the limited means of the apprentice is to shackle him or her finally with triviality, since apprentices do not become masters by using dull tools or toying with their work. It is better in my opinion to support inexperience with patience and encouragement, good tools, and valuable work than to falsify expecta- 
tions or trivialize the work for the sake of some easy sense of achievement.

$A$ case in point was my decision to include foreignlanguage materials in this guide wherever I found them to be without English-language equivalents or to be otherwise worthy of note. To exclude all or most nonEnglish-language reference materials on the grounds that English-speaking students lack foreign languages is to misrepresent the fact that scholars do indeed miss valuable resources under such circumstances. I did not want simultaneously to regret linguistic provinciality and to construct a reference work that made competence in foreign languages seem unnecessary for serious scholarship.

This example holds by analogy with my reasoning throughout this guide, where sophisticated works used by the advanced scholar are cited along with more accessible, elementary tools.

This work is not intended to be of particular use to the specialist in his or her own field. But it should prove informative whenever questions arise about adjacent or ancillary fields. The book therefore retains something of its original character as an information source for the uninitiated, but it also acknowledges that even the most experienced scholar may be an apprentice outside what seem to be increasingly narrow fields of primary specialization. In addition, the publication explosion of scholarly reference works during the last decades makes it possible that even in the familiar territory of a specialization the scholar will find here some unfamiliar works that supplement or complement tools already wellknown and used. Or the scholar may notice here unrecognized features or unexplored uses for works already consulted regularly. In short, this work has been prepared on the assumption that one reference guide might properly serve both the student and the scholar-terms that I have long thought nearly synonymous.

Because of its broad scope the contents of this volume are difficult to characterize in themselves, for it is less their nature and more the scholarly functions they might serve that have led to their inclusion. Thus, where there are no available alternatives, works that are poorly organized, inaccurate, or significantly out of date are included (with appropriate cautions). Where, on the contrary, numerous works are available, the effort has been one of selectivity: appearing here will be the most current, the most accurate, the best organized, and the most useful of the lot. There is, in other words, a marked inequality among items included in this guide: in common is only my judgment of their utility as resources for a particular class of scholarly reference questions. Few works are cited that are concerned with one author or one work. The exceptions include Chaucer (see entries $\mathrm{N}-45, \mathrm{~N}-47$ ), Shakespeare (see 0-40 through O-59), and Milton (see O-28). Further exceptions include the two guides to major-author reference works (see M-60 and S-50). Finally there are occasional biographical or critical works that, though cen- tered on one author or one work, range so widely in treatment as to constitute essential, or at least frequently recommended, reading for students of a particular period or genre (as, for example, Tolkien on Beowulf, Brower on Pope, or Ellmann on Joyce). Access to such works is easiest through the author-as-subject entries in the Index of Subjects.

This guide only occasionally cites article-length materials, on the grounds that most articles of surpassing value become anthologized or develop into books - and many such collections and books are cited in lists of frequently recommended works. There are, however, occasional exceptions to this limitation, dictated by my judgment that in a particular case an article is in fact of such importance or stands so utterly alone in its field as to make citation necessary.

\section{OTHER USES OF THIS GUIDE}

The primary use of this guide, then, is to locate appropriate tools to consult for a particular reference question. But it does have other uses. Because of its scope it provides a survey map of reference resources in contemporary English studies. Thus it will offer an initial reference bibliography for any field or subfield of English studies, including both basic and advanced reference tools, and both scholarly journals and frequently recommended scholarly books. Again, the specialist would not look here for that bibliography, having long since become aware of the tools of his or her trade. But the apprentice preparing for an examination in, say, English romanticism and the visitor from another specialization suddenly assigned to design and teach a course in children's literature, or a survey of commonwealth literature, or a general education course in the art of biography will turn with profit to the relevant sections of this guide.

Because of my intention to help the English-studies researcher become self-sufficient in the library, this guide also provides librarians with a fairly comprehensive introduction to and overview of a contemporary English studies reference collection. In comparison with general reference guides such as Sheehy (A-20), Walford (A-21), Malclès (A-22), or Totok (A-23), this guide is more specialized. It includes a wider range of tools and describes them from a more specific point of view- that of the research scholar. Thus it would be an appropriate resource for more specialized reference librarians, those concerned exclusively with English studies, or languages and literatures, or even humanities reference.

\section{CAUTIONS ABOUT INTENTIONS}

Given such broad purposes and extensive uses, it may be well to indicate forcefully what this volume is not intended to do. First, it does not claim bibliographical authority. While pains have been taken to make entries bibliographically accurate, my central concern and principal occupation have been to make them informative. 
Readers needing precise citations will therefore wish to verify bibliographical information for all entries by consulting standard authorities such as the National Union Catalog (see B-10 and B-11).

A second use to which this guide should not be put is as a closed bibliography aiming at anything like completeness. As a guide, it is, in fact, extremely selective, even in the reference works it cites. The rationale for an item's inclusion is its utility as a current reference source and not simply the fact of its existence. And though I may have overlooked works that should be admitted under that principle, missing items, particularly if published before 1985, may have been considered and silently excluded on the grounds that something more useful was available. While I might have appended a list of the hundreds of works thus considered but excluded, I decided that such a list would serve too narrow a purpose for the space it would take and the offense it might cause. Suffice it to say, then, that many more inclusive bibliographies of reference tools are available in such standard works as Howard-Hill (M-1, 0-45), the New Cambridge Bibliography of English Literature (M-11, N-11, O-11, P-11, Q-11, and R-11), Nilon (S-1), and the Literary History of the United States (S-10), to mention only four leading works of wide-ranging scope and much broader principles of inclusion (though they differ significantly one from another in this regard).

The third and most serious misunderstanding of this volume would be to see it as somehow presenting or representing a consensus or corporate evaluation of the reference system for English studies. For good or ill, this massive volume remains the work of a single individual. It has, then, a degree of coherence and evenness of treatment that no guide composed by a committee could hope to have. At the same time this single perspective is an obvious limitation, for no individual, however indefatigable, can hope to provide either the depth or the range attainable in a large collaborative project. It may be that a subsequent edition of this guide-one informed and corrected by the help of its users and critics in all specialities-will be able to carry a more general authority than is currently possible. Indeed, such a broadly based, authoritative guide to reference sources for English studies remains a desideratum. But the present volume must be regarded as a single individual's view of what, in the interim, will be most helpful.

\section{ENTRY TYPES}

There are three types of entries in this guide. First and most frequent are entries concerned with a single work of scholarly reference. Basic bibliographical information is provided along with a description of the reference work's history, purpose, principles of inclusion, arrangement, and special features. In addition, supplementary and complementary works are cited, along with cross-references to otherwise related tools.

For further guidance about the character and use of a particular reference work (and, given the caveats suggested above, to compare my annotations with additional or alternative sources of opinion) users are referred to section E.VI, Reviews, and to the Index of Subjects entries under "Reviews" and "Bibliographic essays."

The character of my annotations is deliberately dynamic, as they are intended to provide prospective users of a reference work with information concerning it. The prospective user will find my annotations sufficiently extensive to form what will turn out to be accurate expectations about a work's utility. Some white space has also been left for users of this guide to add further annotation of their own.

A second type of entry lists scholarly journals in particular fields. The most recent title of the journal is given (along with some previous titles); the current place of publication and publisher are cited (along with some former places and publishers); the beginning date and frequency (or range of frequencies) of publication are given; whether the journal includes reviews or a current bibliography is indicated; and whether and where it is cumulatively indexed is stated. The user should not (to repeat) rely on these entries only. For full, bibliographically authoritative publishing histories of each cited journal, see the Union List of Serials (D-90) and New Serial Titles (D-91), along with other serials authorities described in section D. See section D, also, for entries on general periodical indexes and guides to indexing and abstracting services that might cover a particular journal.

In these journal lists, my effort has been to strike a balance between including every possible journal in a field and including only the most important. There are nearly fifty such lists of journals interspersed through the various sections and subsections of this volume; a master list appears on page xxxvii.

The third type of entry is the guide list of frequently recommended works in a particular field. The purpose of these lists is to present handy working bibliographies. Authors, titles, and places and dates of publication are indicated, along with Library of Congress call numbers. While every specialist will know of items that might readily be added or deleted from each list, few will find that an included item has no serious claim to a potential user's attention or that an item generally thought indispensable is missing. I urge users to regard these lists with all the suspicion proper to bibliographies assembled by a nonspecialist. In working with this type of entry especially the user should remember the caveats mentioned above and that this book presents the judgments of a single individual. There are about 150 such lists interspersed throughout the various sections 
and subsections of this guide; a master list appears on pages xxxix-xlii.

One subclass of entries in this category consists of the guides to major English and American authors (at M-60 and S-50 respectively). As is true of every other evaluative decision made in completing this guide, the designation of "major" status reflects my own judgment of iwhere to draw the line. These lists could be enlarged easily and almost as easily contracted. In this case, as in so many others, a degree of arbitrariness is simply unavoidable and might as well not be disguised. In view of the ongoing, radical expansion of the canon, these sections will undoubtedly seem among the most conservative elements in this work, a work in which I have constantly tried to steer a moderate course between the tradition of English studies and the immediate scene in all of its tumultuous vitality.

\section{ARRANGEMENT}

Every reference work expresses its author's conception of the field it covers, and this work is no exception. But to interpret my expression correctly, some metadiscourse may prove helpful. I think it within neither my province nor my prerogative to predict the no-doubt related outcomes of the current critical wars in literary theory and the current contentions for control of the institutions of English studies. Nor have I wished to define the ultimate relationship which will emerge between English studies as practiced during the last twenty years and the tradition of studies which have gone before. I have, however, accepted the dual obligations to represent available reference tools, many of which emerge from traditions of study no longer current, and to represent possible reference queries which will emanate not only from the immediate present, but from the foreseeable future of English studies, whatever their various contemporary forms will take. I thus envision a large and relatively stable terrain, with relaxed but determinate, well-traveled borders to neighboring fields, which has recently been disturbed by natural disasters, zoning changes, and the arrival of various new inhabitants, variously related, whose presence is of uncertain duration and significance.

The arrangement of this guide is accordingly complex. I have chosen a table of contents which allows a set of twenty-four unequal sections (not called or considered co-equal chapters) on whole large topics of interest (Section B-Libraries, Section F- History and Ancillae to Historical Studies, Section Z-The Profession of English); broad general classes of reference works (Section A-General Reference Guides, Section C-National Bibliography, Section D-Serial Publications); large general categories of literary study (Section I-Language, Linguistics, and Philology; Section K-Literary Materials and Contexts; Section U- Theatre and Drama; Section W-Prose and Prose Fiction); traditional periods of English literary study (Section N-Medieval, Section O-Renaissance, Section Q-Nineteenth Century); and the always anomalous field of American Literature-Section S.

I have placed new fields of study within sections where they seemed to find a plausible location (e.g. Folklore, Symbology, and Intellectual History in Section K-Literary Materials and Contexts; Children's Literature and Women's Studies in Section I-Literature; Commonwealth Literature in Section M-English Literature; Chicano Literature in Section S-American Literature; and Structuralism and Deconstruction within Section X-Literary Criticism and Literary Theory). And $I$ have relied throughout on my intention that the user would begin an inquiry with the Index of Subjects rather than the Table of Contents, knowing that the index format would allow me most readily to point out where tools on particular topics or texts were located, since an inquirer's topic or text might include works found in half-a-dozen or more locations within this volume. Such reliance, I thought, freed me from having to design a table of contents by either ignoring or having to settle the very issues that make English studies today so exciting and so intractable. My arrangement is thus an act of evasion which is also, I believe, an act of appropriate modesty. Mediating between the evasions of the table of contents and the multiple access points of the index are the numerous cross-references, designed to guide a user to such related materials as I imagined would most likely interest him or her.

Main entries, lists of journals, and lists of frequently recommended works are arranged, then, in twenty-four major sections from $A$ to $Z$ (excluding $J$ and $V$ ). Within sections, entries are further disposed into subsections. In general, the sequence of entries moves from more general to more specific works and from more distant subjects and types of tools to those more immediately and narrowly related to English studies. The lists of scholarly journals and of frequently recommended works generally come near the end of the sections or subsections to which they pertain.

Sections A through $E$ concern the most general sorts of bibliographical and reference tools: bibliographies of bibliographies; general reference guides; encyclopedias; library guides; national bibliographies; periodical bibliographies, indexes, and finding lists; tools useful in locating and using dissertations, microforms, reprints, reviews, composite books, dictionaries of anonyms and pseudonyms, and both films and spoken recordings from literary works. Sections F, G, and $\mathrm{H}$ treat history and ancillae to historical study; biography and ancillae to biographical study; and manuscripts and archives, along with aids for their study. Section I, on language, linguistics, and philology, is followed by section $K$ on literary materials and contexts, including reference works in the fields of folklore, mythology, Bible study, 
proverbs, quotations, symbology, and stoff und motivgeschichte. The guides to historical contexts which conclude section $\mathbf{K}$ list in one place standard works in social and cultural history; works on costume and courtesy; works on the history of taste and related problems; works on intellectual history and the history of ideas; and finally studies in the history of learning, including education, scholarship, and librarianship. These lists alone make it imperative that users not expect to find all works pertinent to a certain broad subject area-Eighteenth-century studies, for example-enumerated in one place. Many are in section $P$, on the Restoration and Eighteenth Century, to be sure, but others are here in section $\mathrm{K}$, and there are pertinent works in a dozen other sections, all of which are identified in the Index of Subjects.

Section $\mathrm{L}$ begins the specifically literary focus of this guide and treats general and comparative literature; general literary dictionaries; classical studies; and modern languages and literatures (except for the English language and its literatures); along with the newest fields of general literature: children's literature, and women and literature. Section $M$ treats English literature, with separate sections on Scottish, Welsh, and Irish studies, along with Commonwealth literature and world literature written in English. Sections $N$ through $R$ cover the traditional periods of English literary history: medieval, Renaissance, Restoration and eighteenth century, nineteenth century, and twentieth century.

Section S treats American literature, with sections on local and regional literature and on ethnic American languages and literatures. The genres follow in sections $\mathrm{T}$ through $\mathrm{W}$, treating poetry and versification; drama, theater, and film; and prose fiction and nonfictional prose respectively. Section $X$ concerns reference works in the fields of literary theory, rhetoric, and composition; $\mathrm{Y}$ includes the fields of analytic and enumerative bibliography, textual criticism, the history of the book, book collecting, and libraries and librarianship. Section $\mathrm{Z}$, finally, treats works concerning the profession of English, including historical studies, directories of scholars, expositions of purposes and methods of scholarship, and guides to research, to research methods and techniques, to computer-assisted research, to grants and fellowships, to publication, to the job market, to pedagogy, and to alternative careers. It thus brings the arrangement back full circle to the broadest and most general contexts for the work of English studies.

Within these twenty-four major sections, arrangement generally moves from guides and reviews of research to standard closed and serial bibliographies, to other reference works, such as encyclopedias, companions, dictionaries, and standard reference histories. Subsections of sections concerned with one period of literary history treat works on the poetry, drama, prose fiction, and nonfictional prose of the period. Subsections within the three genre sections include the major subgenres. Subsections in section $\mathrm{L}$ treat the major literatures of the world; those in section $\mathrm{M}$ treat each of the major Commonwealth English literatures; those in section $S$ treat each of the major regional and ethnic American literatures. The Overview of the Organization of this Guide (pp. xxxi-xxxvi) will aid the user in grasping this organization more completely.

In arrangement of sections and sub-sections, I sought to steer a middle course between an overly simple and an overly elaborate organization. A very simple organization would have been entirely inadequate; a fully systematic arrangement would have left users entangled by complexity. Thus there are numerous divisions and subdivisions, but I have not sought to make them all follow a single system of categories; they are convenient rather than logical divisions and are meant to be overstepped or ignored as necessary in an individual researcher's use of the work.

Still there should be no illusions about the value of this arrangement. It is a relatively flexible and thus fairly realistic way of organizing a vast, various, and everexpanding volume of materials. I do not mean for the Short-Form Listing of all main entries (pp. xliii-lxxii) to be the only or even the best (though it will probably be the most frequently used) means of access to the contents of this volume. And I suspect that the experienced user will not treat it as such.

Given the Guide's functional emphasis and the multiplicity of uses to which almost any reference tool can be put, experienced users will learn to turn first to the detailed Index of Subjects. There in a single alphabet will be found the most convenient means of locating all the tools likely to be worth considering for a particular reference question. Index entries include not only the subject matter of reference works but also terms referring to their type ("indexes and indexing-newspaper," "student bibliographical guides"); their arrangement ("arrangement-chronological"); and the character of their entries ("short-title catalogs," "bibliography, descriptive").

In addition to the Index of Subjects, users will find an Index of Authors, Compilers, Contributors, and Editors; and an Index of Titles. There are also cross-references at the beginnings of most sections and subsections and cross-references within entries. These constitute yet another means of reorganizing this guide. My practice in cross-referencing has been to cite a work under any heading where it makes a fundamental contribution, either because it is itself a major tool (but classed in another section where it is also of the first importance) or because the paucity of available works is such as to make it an essential resource, though it is a work of more general utility. Cross-references between period and genre listings are examples of the first type; repe- 
ated cross-references to the MLA International Bibliography (L-50), the MHRA's Annual Bibliography of English Language and Literature (M-21), the Year's Work in English Studies (M-22), and American Literary Scholarship: An Annual (S-13) are examples of the second sort of cross-reference.

The full entry for each reference work appears, however, only once in the volume, in the place where it seemed to me most appropriately cited. These judgments are not always obvious in their logic, however, and I have had to rely on a number of rules according to which I have placed certain items.

If a work is confined to one literary period (or a part of a period), its main entry is placed within the section concerning that period. Thus, the Old English Newsletter is in section N, on medieval literature, subsection on Anglo-Saxon ( $\mathrm{N}-22)$; the journal Contemporary Literature is in the list of scholarly journals in section $R$, on the twentieth century (R-18); and the standard work of F. O. Matthiessen on the American Renaissance is in the list of frequently recommended works on American literature (S-19).

If a work is confined to one genre, the work is in the section concerned with that genre. Thus Ian Watt's The Rise of the Novel is among frequently recommended works on the novel in section W, on prose and prose fiction (W-9), rather than in eighteenth-century studies, though no serious student of the eighteenth century will want to miss reading it, even if its scope is ultimately broader than a treatment of the eighteenthcentury novel. In contrast, Ronald Paulson's Satire and the Novel in Eighteenth Century England is cited among the frequently recommended works for eighteenth-century studies (P-19), for though it treats the novel, its treatment is confined to novels of the eighteenth century. But Paulson's Fictions of Satire, which treats some eighteenth-century novels, is in section W, among frequently recommended works on satire (W-159), for its focus is broadly generic.

If a work treats one genre in one period, as in the above example, the entry is in the genre subsection of that period's section. A frequent exception is when such a work helps to constitute what might be regarded as a multivolume series, in which case it will be cited in the genre section. The London Stage 1660-1800, $1800-1900$, and 1890 - will be found in section $\mathrm{U}$, on drama and theater (U-77, U-78, U-79), rather than in sections $\mathbf{P}, \mathbf{Q}$, and $\mathbf{R}$. Similarly, Chambers's Elizabethan Stage, though it is as essential a work of reference for the student of Renaissance drama as the stage calendars are for students of eighteenth-, nineteenth-, and twentieth-century theater, will nevertheless be found in section $U$ beside his work on the medieval stage and the works of Bentley on the seventeenth-century stage and Harbage on Cavalier drama (U-73, U-74, U-75, U-76). Another important exception is when the work is among several that together constitute the history of the genre. Thus Hallet Smith's Elizabethan Poetry is at T-49; Robert D. Hume's Development of English Drama in the Late Seventeenth Century is at U-80; and Kathleen Tillotson's Novels of the Eighteen-Forties is at W-49.

American literature is treated in a separate section, though works relevant to its study are found in virtually every section of this volume. When a work treats American or indeed another of the world literatures written in English along with British literature, it will most likely be found in section $\mathbf{M}$, along with other works concerned exclusively with English (that is, British) literature. But the user with a question concerning some particular aspect of American literature or American studies would best consult the Index of Subjects, where references are made from a multiplicity of subject terms, rather than the table of contents, where each item if cited at all can be cited, alas, only once, no matter its complexity or variety.

\section{OTHER FEATURES}

Standard abbreviations and short titles for journals and major reference works are given in brackets after the full title. Also provided, when possible, are Library of Congress call numbers. Note, however, that LC numbers are uniform only in their first elements, the letters and numbers that identify the subject area of the work. Subsequent elements (and particularly those identifying authors and editions) may vary slightly in other libraries that nevertheless use the LC system. The numbers cited here are those actually used at the Library of Congress, where most of the work of preparing this Guide took place. Most users will find the deviation from this number at their research library relatively slight and will, therefore, have use for this feature.

Here and there some not-yet-published works are cited, but only when they are likely to be worth consulting as soon as they are published-that is, when they fill a gap in existing resources.

Features that some reference guides have included but that I have excluded are citation of Dewey decimal numbers (on the grounds of their infrequent use in research libraries); reference to the rapidly changing facts of microform versions or reprints (see the pertinent reference tools in section E.IV, on microforms, and E.V, on reprints); and reference to the even more rapidly changing facts of publication: prices, paperback editions, and in-print status (see tools in section $\mathrm{C}$ such as Books in Print, C-39).

\section{SOME PECULIARITIES}

One oddity that users will probably regret, but which I found expedient for indexing and other purposes, is my decision to delete initial definite and indefinite articles 
in English-language titles except in the titles of works of literature. Another peculiarity is my decision to exclude lists of frequently recommended works from the indexing process, save that the general subjects of those lists are included in the subject index.

There are also peculiarities arising from the once ground-breaking but now antiquated main-frame word processing and document design programs through which this book has been typeset. These include unusual hyphenation practices, particularly in foreign language words, and sufficient formatting difficulty to make it necessary sometimes to accept titles in one column whose description is in another. While an effort has been made to over-ride these automatic inelegancies, it has not been possible always to catch or to cure them.

One consequence of the unusual manner in which this book has been typeset is that it has taken several years to complete the process. While an effort has been made to add important new titles, they have sometimes for convenience sake been appended as ancillary titles to an earlier entry when they should under more flexible circumstances have changed places and become main entries themselves.

I am aware, also, of the unfortunate peculiarity that this volume fails consistently to practice nonsexist usage, particularly in my more than occasional employment of masculine pronouns and references in their "generic" sense. I have myself only recently been able to acknowledge the offensiveness of this practice and I apologize for it. I am also aware of, but was unable to act on the need to change "Afro-American" references to the preferred designation of "African-American."

\section{FURTHER CONCERNS}

Although I have worked alone on this guide, I have not been without the benefit of colleagues and friends who have given advice freely on most sections and whose help is acknowledged below. But the University of California Press and I recognize the opportunity that only publishing creates to secure the advice of hundreds of colleagues about errors of exclusion and inclusion, errors of fact, of emphasis, and of judgment. We will be grateful for the receipt of all such advice and hope to incorporate it in a revised edition. Needless to say, all such errors remain my sole responsibility.

It is difficult ever to let a book of this sort be published. As has been true for each of the last twelve years of work on A Reference Guide for English Studies, yet another year's tinkering will certainly improve it. But there is no end to such effort, and every year of tinkering brings on another year's worth of revised, supplemented, and new reference works that must be evaluated for inclusion. As it is, the entries in this volume are current only through 1985 or so, though I have made considerable effort to cite later items as they came to my attention. Because the entire text is stored on computer, it has been possible continuously to revise and update it until the point at which camera-ready copy was generated, roughly six months before actual publication. Still, if this book succeeds in being the guide I have intended to write, a later edition will certainly improve on this one.

I cannot conclude this Preface without referring users to the Acknowledgments. Though this has been a single and quite lonely project, my work has been supported at every tum by colleagues and friends. Without their interest, encouragement, and help, I would never have been able to bring it even to this provisional conclusion.

College Park, Maryland

December 1989
Michael J. Marcuse 
